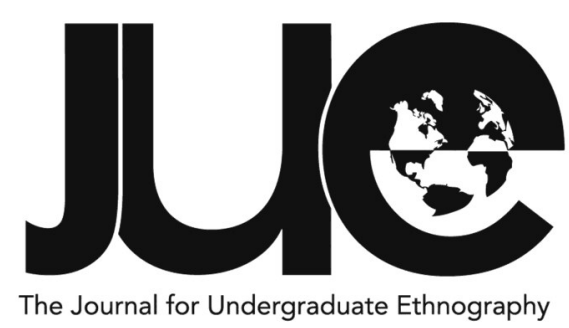

\title{
No Façade to Hide Behind: Long-Distance Hikers' Journeys Through Self and Society
}

\section{Lauren Reiss}

University of Massachusetts, Lowell, laurenelizabethreiss@gmail.com

\section{ABSTRACT}

This ethnographic study uses a phenomenological approach to better understand how Appalachian Trail (AT) and Long Trail (LT) thru-hikers create meaning and make sense of their experiences while hiking. Drawing on participant observation and in-depth interviews with 13 hikers, I analyze hikers' initial reasons for hiking, their reflections while on the trail, and the impacts thruhiking had on their self-concepts and social lives. Key findings demonstrate how life on the trail contrasts with hikers' everyday lives in society and thus suggest ways that their experiences on the AT/LT may give insight into nature, community life, personal change, and the process of personal reflection. In particular, this study suggests that long-distance hiking builds personal skills and confidence. Further, this research uses a phenomenological approach as well as the concepts of liminality and communitas to analyze the creation of an alternative trail subculture and new personal identities on the trail, including trail families.

Keywords: Long-distance hikers; phenomenology; ethnography; liminality; self-reflection; communitas 
n 2013 when I was 23 years old, I ventured off on a three month, 800-mile stretch of the Appalachian Trail from Erwin, Tennessee to Duncannon, Pennsylvania. While on the trail, I adjusted to living amongst the elements, building leg muscles, and sleeping outdoors, which was a radical change from living indoors with all of one's creature comforts. During the first week, I hiked through freezing temperatures, sleet, high winds, and up icy mountain-tops-some of the most intense hiking conditions I had ever experienced. After a few days on the trail, my friend Lace and I were coming to the end of our miles for the day. We didn't have much time before sundown and were heading up a mountain to get to an old cabin that was converted into a shelter. The trail up this mountain was covered in ice, so the only way up was by grabbing on to thick tree trunks and pulling ourselves up with our 40pound backpacks on. The trail was so slippery and dangerous that the only safe way to go was very slowly and cautiously.

This period of my young adult life was very much one of transition: a time when I was reflecting on what I wanted to strive for in life and what type of job I wanted to pursue. My own experiences on and off the trail made me curious about the different reasons why people decide to embark on a long-distance hike and how they reflect on their experiences. For example, how might personal identities change on the trail, and how are new social relationships and communities formed? In what ways does this new trail culture contrast with hikers' everyday lives both before and after their long-distance hikes? And what is the role of personal reflection in this process?

With these questions in mind, this research aims to better understand how Appalachian Trail (AT) and Long Trail (LT) thru-hikers create meaning and make sense of their experiences while hiking. Initial reasons for hiking, experiences on the trail, and the impact of thruhiking on hikers' self-concepts, personalities, relationships, and creation of a new sense of community will all be explored. Further, this research utilizes the analytical concepts of liminality and communitas to analyze the creation of an alternative trail culture and the emergence of "trail families," as well as a phenomenological approach to understand how new personal identities are formed and experienced on the trail in contrast with the everyday realities hikers return to once their hike is completed.

\section{Ethnographic Studies and Personal Memoirs about Long- Distance Hiking}

Over the last decade, long-distance hiking trails have become popularized through films and books such as Cheryl Strayed's Wild: From Lost to Found on the Pacific Crest Trail and On Trails: An Exploration by Robert Moor, which was inspired by the author's experience thru-hiking the Appalachian Trail. Several studies have also been conducted on long-distance hiking and specifically on hiking the Appalachian Trail. Susan Bratton's (2012) research explores how long-distance hiking can assist someone in making a life transition, gaining self-confidence, providing relief from stress, or helping to resolve major changes in personal relationships. Furthermore, hiking can stimulate spiritual growth and act as a restorative environment that is not solely based on contact with nature, but also focuses on being away from the constraints of everyday life and having time for personal reflection. Kristi Fondren's (2016) study focuses on the sociality and social practices of the long-distance hiking community and what impacts recreational settings have in the formation of leisure subcultures and subcultural identities. Fondren views longdistance backpacking as a resistance to societal structures and values of modern life such as monetary gain, media influence, consumerism, materialism, and the bustle of work and family. Lucy Bosche's (2013) work discusses women's experiences navigating the subculture of the Appalachian Trail and Pacific Crest Trail through memoirs and trail blogs using Victor Turner's 
concepts of liminality and communitas. Bosche discusses the transformations hikers undergo through experiencing liminality as they become immersed in trail life and establish an alternative identity through a trail name.

Turner's (1969) concepts of liminality and communitas similarly inform this research by providing lenses to understand the transformation a long-distance hiker may undergo as they leave the structure of their everyday lives and relationships and embrace a new identity and reality on the trail. Longdistance backpacking is a pursuit that requires one to uproot one's life and leave behind family, friends, obligations, and work to experience something different than one's everyday life. For this reason, endeavoring on a long-distance backpacking trip can be viewed as a period of liminality. Liminality is a sociological/ anthropological term first noted by van Gennep ([1909] 1960) and later used by Victor Turner (1969) to describe an ambiguous phase of being in the middle of a transition, an in-between period in which one has not fully transitioned from one thing to another. During this period, the norms of everyday life no longer apply and participants undergo a restructuring of their identity, time, and community and enter into a new way of life. Liminality is often associated with the middle part of a rite of passage, which may be defined as a ritual marking a life transition from one social status to another (Turner 1969).

Additionally, a liminal state is often brought about unexpectedly, as in the case of refugees and some migrants, and can persist until the person reintegrates into a new identity. In contrast to this type of liminal state, thru-hikers voluntarily choose when to begin and end their liminal state of life on the trail. Similarly, I argue that the trail often constitutes a transitional period between one chapter in a person's life and the next. One way that hikers on the AT/LT restructure their identity is through adopting a trail name that is symbolic of a new start, a rebirth. Trail names are typically given from one hiker to another and highlight some sort of quirk about that individual. However, some hikers create their own trail name. Hikers also tend to adopt values of free expression and non-judgment on the trail, which contributes to their newly formed identities.

Communitas, another concept that Turner (1969) discusses, refers to an unstructured community of people wherein all members are considered equal and are united by a common experience, usually a rite of passage. Communitas also refers to the spirit or common feeling of people experiencing liminality together. Communitas is formed on the trail as hikers bond over their shared experience and newly adopted values and create trail families.

In contrast to earlier studies, my research uses a phenomenological approach to understand the process of personal transformation as hikers make sense of their experiences on the trail. Endeavoring on a longdistance backpacking trip can alter a person's sense of reality and identity due to exposure to vast differences in social realities from everyday life to the culture on the trail. Phenomenology is defined as "the study of things as they appear in our lived experiences" (Desjarlais and Throop 2011,88 ) and addresses how people construct social reality in their everyday lives (Lemert 2017; Ritzer 2018). As explained by Berger and Luckmann (1966), in human society the social construction of reality involves an ongoing dialectical relationship between externalization, objectivation, and internalization (149).

Berger and Luckmann (1966) further suggest that externalization occurs when humans perform various habitual actions that create and shape social structures and institutions, formulating typical assumptions, expectations, and behaviors. These social structures and institutions then appear to have their own independent and objective existence that has power over us. Internalization is the process in which we internalize this objective social world, which then becomes part of our identity. However, both individual and social experiences may cause one's pre-existing social reality to conflict with a new reality, which may result in a radical change of perception of themselves and their social relationships (Berger and Luckmann 1966).

A phenomenological perspective helps us to consider the image that thru-hikers have of 
themselves prior to hiking the trail and how this may change on the trail. Contradictions of what one considers "normal" might occur, as exposure to the subculture of the AT/LT could cause one to question their perceived reality of everyday life, at which point one can then choose which reality to accept. Opportunities for incongruities to arise between one's primary relations such as family and friends and secondary socialization such as other thruhikers may arise, which also encourages thruhikers to question their perceptions. Endeavoring on a thru-hike takes the person outside of their ordinary experience, revealing and bringing into question many things that they have taken for granted up until that point, which may lead the hikers to radically change their perceptions. One is found within a new reality. In such insightful moments the veil is lifted and one is able to view their experience differently, which makes one realize that a new reality can be constructed (Berger and Luckmann 1966). In this way, we are able to understand how a hiker's sense of self, community, and society may change as a result of their exposure to the subculture of the AT/ LT. While an extraordinary moment of insight can be enlightening, it cannot be sustained over time; however, it does create a new social order and allow new habits to arise (Berger and Luckmann 1966).

Importantly, focusing on how personal change occurs on the trail does not suggest one particular reality or only individual realities for hikers on the trail. On the contrary, multiple subjective and intersubjective experiences exist. Phenomenologists argue that subjectivity is deeply intersubjective in nature (Desjarlais and Throop 2011, 91), stressing how social interaction may influence our sense of self. While phenomenology looks at individual experiences and reactions, it also emphasizes multiple realities unfolding through social interaction. On the other hand, communitas not only highlights social bonding such as within trail families, but also emphasizes individual identity. In the words of Edith Turner (2012), communitas "does not merge identities; the gifts of each and every person are alive to the fullest" (3). A radical change in perception can be brought about simultaneously through selfreflection and communal engagement. While these differing phenomena may appear to contradict each other, subjective and intersubjective experiences are happening simultaneously and make up the complexity of the overall experience for thru-hikers.

This process brings into question how hikers' newly constructed identities are formed and to what extent their newly formed identities carry over into their everyday lives after finishing their thru-hike and reintegrating back into the larger society. This is the first research study about Appalachian Trail thru-hikers using a phenomenological theoretical approach with an explicit focus on the process of personal reflection.

\section{Methodology}

This study uses ethnographic research methods, which include participant observation and in-depth interviews with 13 long-distance hikers who have completed or who were currently hiking on the Appalachian Trail and Long Trail during the time of the interview. Ten participants were recruited on the AT/LT in southern Vermont. Three participants were thru-hikers who had previously completed the AT in 2013 and were contacted and interviewed via phone or in person.

In July of 2019, I backpacked on a section of the AT/LT in southern Vermont for five days. During this time, I conducted participantobservation through backpacking, personal reflection, interacting with other hikers, and recording my experiences (see figure 1). Having previously hiked a large section of the AT and being a participant-observer helped me to establish rapport as another hiker on the trail rather than as an outsider coming in. Hiking on the trail and being part of the community seemed to increase trust between me and the hikers I interviewed. The hikers might have talked with me differently if we had not shared this experience.

Throughout the interviews, my own personal background as a hiker also helped to facilitate conversations as I could relate to interviewees from my own experiences while on the trail. At the same time, I avoided projecting my own experiences onto others by asking neutral questions and listening carefully and nonjudgmentally to responses. 
I collected demographic information about each hiker, including age, gender, race/ ethnicity, economic comfort level, religion, employment, place of residence, and education. I then asked hikers questions about their motivations before hiking, experiences while on the trail, and impacts after completing the trail or anticipated impacts of hiking the trail on reintegration. My questions included what prompted them to do a long-distance backpacking trip on the AT/LT and what their intentions, expectations, and hopes were before going on the trail. Information about each hiker's experience while on the trail was collected by asking about their overall experience, personal reflections, how spending extended periods of time in nature affected them, the culture of the AT/LT, and how it differed from everyday life. I also asked hikers

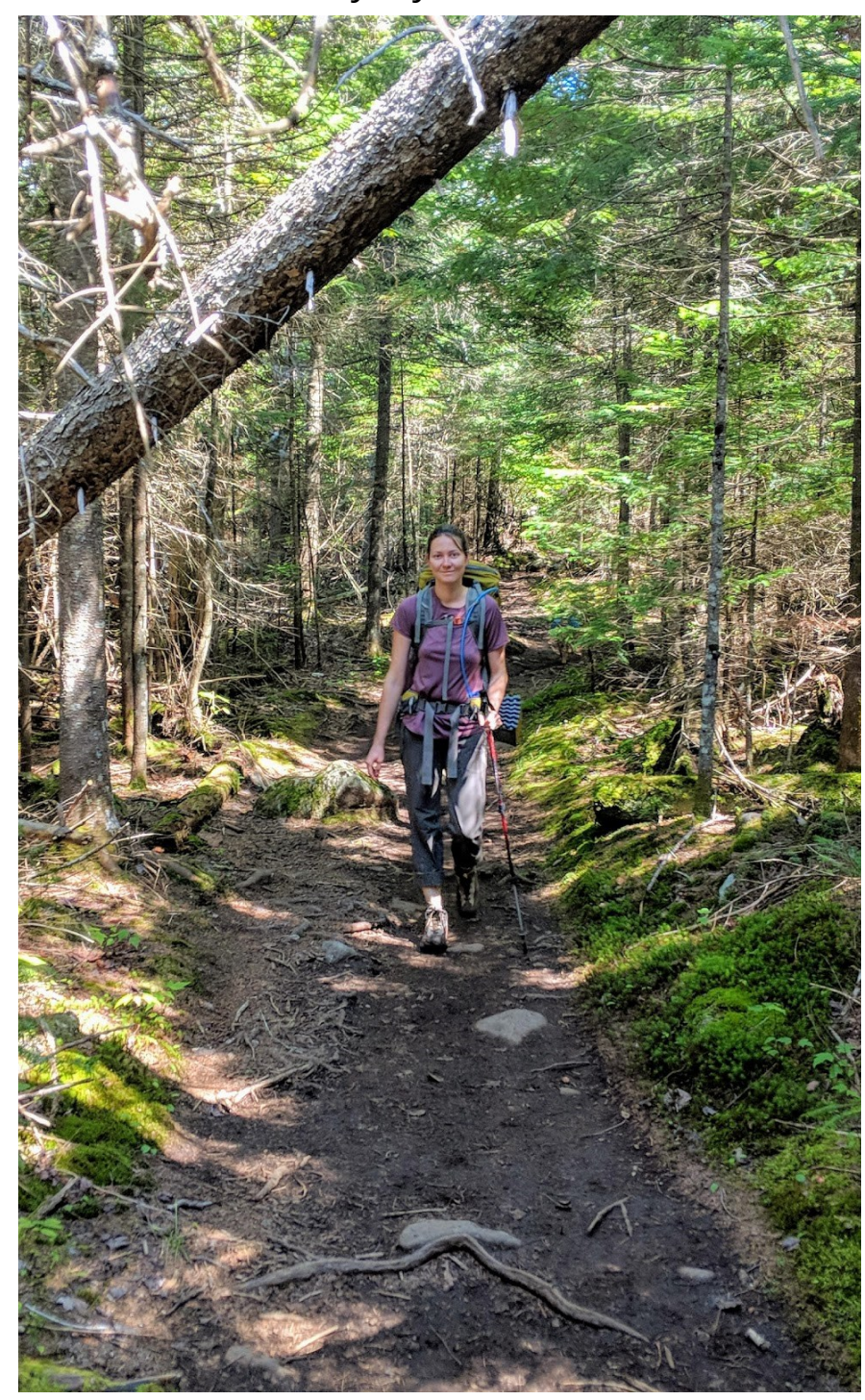

Figure 1. Backpacking and conducting participantobservation on the AT/LT. how thru-hiking impacted their views of themselves, community, and society and about their experience or anticipated experience of reintegration and lifestyle changes after hiking the trail. I changed hikers' trail names in this study in order to keep their identities confidential. I transcribed, coded, and analyzed the interviews thematically using qualitative data analysis techniques (Esterberg 2002). I also compensated hikers with Dunkin Donuts gift cards and s'mores.

\section{Location Overview}

The Appalachian Trail (AT) runs about 2,200 miles long along the eastern side of the United States between Springer Mountain in Georgia and Mount Katahdin in Maine. The AT passes through 14 states and is the longest hiking-only trail in the world. The Long Trail (LT) is a hiking trail that coincides with the AT in southern Vermont, runs along the ridge of the Green Mountains, and runs north to the Canadian border. The LT runs the length of Vermont at 273 miles. This research was conducted on the AT/LT in southern Vermont on an 11-mile stretch between Peru Peak and Little Rock Pond. Interviews were arranged at two different locations on the trail, including Peru Peak Shelter and Little Rock Pond Shelter (see figure 2).

\section{Participants}

In this study, ten out of thirteen participants were male and eleven out of thirteen hikers were white, which is typical of AT/LT hikers (Bosche 2013). Two hikers were of mixed race. Most hikers reported being comfortable with their socioeconomic status and not struggling to get along (see table 1). I used this term because I did not want to make my interviewees uncomfortable by prying into their socioeconomic status, and I was mainly interested in understanding their selfperception of whether they felt like they were economically struggling or not.

\section{Data Analysis}

\section{Reasons for hiking}

My discussions with the thru-hikers revealed various attitudes about their intentions and expectations of hiking the trail. The hikers' ages and positions in life shaped their motivations for setting out to thru-hike the Appalachian 
Trail or Long Trail. Common responses to what prompted hikers to thru-hike the AT/LT were to navigate a transition in one's life, gain perspective or to get to know oneself better, take an opportune time in one's life to fulfill a

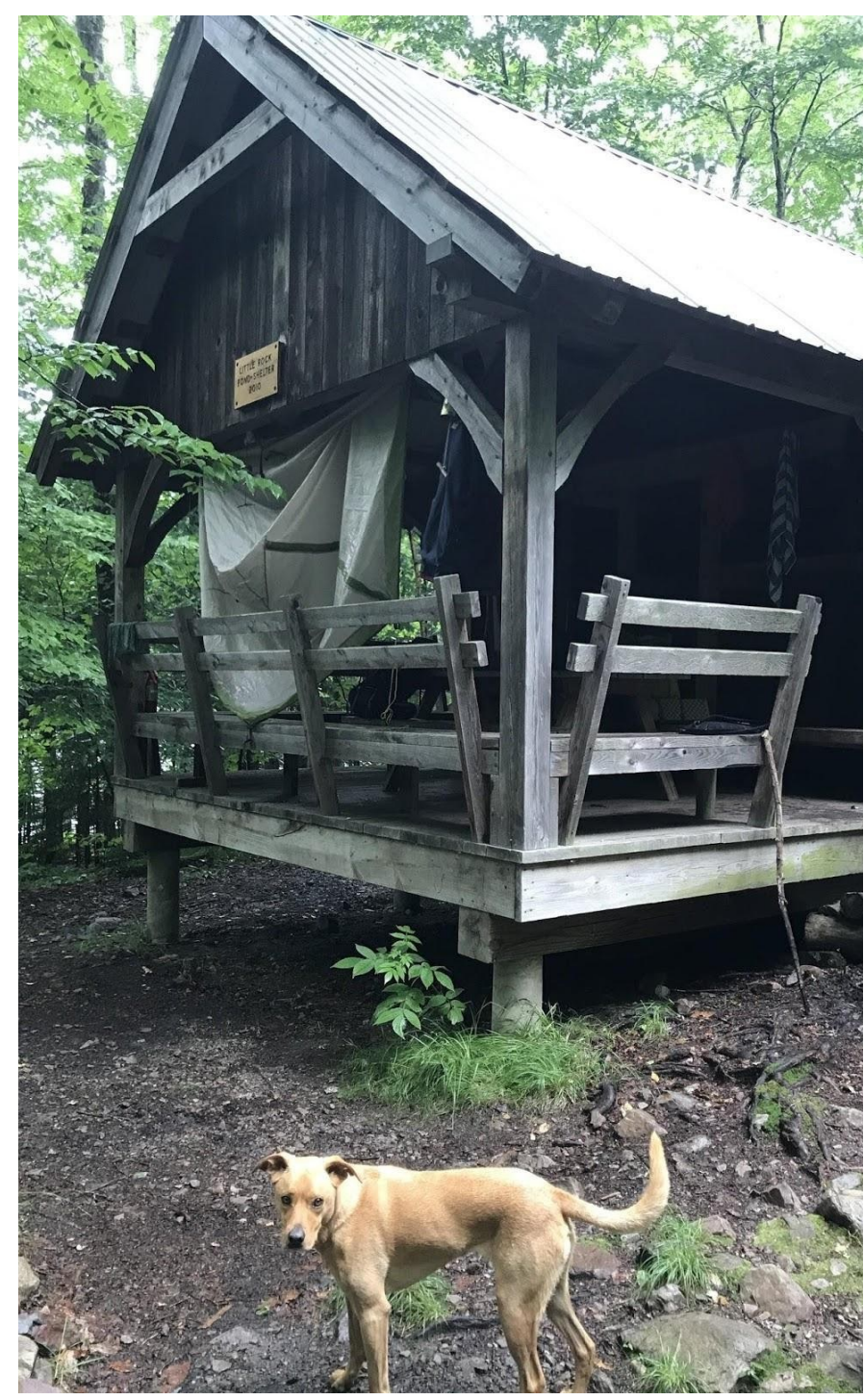

Figure 2. Little Rock Pond Shelter on the AT/LT

bucket list experience, and seek challenge, freedom, or adventure. Some thru-hikers were seeking a way to disconnect from their current situation, including school, a career, or an unhealthy living or social situation, in hopes of initiating a change. Hikers saw that the trail offered a way to handle a change in one's life. For some, the trail was a way to resolve an internal conflict about the direction of their life or the kind of person they wanted to become.

One hiker named Pilot from Massachusetts, who completed his thru-hike in 2013, was previously a student before starting on the AT. Pilot discussed his impulse to hike as a means to contemplate his major and the direction of his career. Another hiker named Aqualad, who is a student from Montreal, Canada, was seven days into his hike on the Long Trail in Vermont when I met and interviewed him. Aqualad expressed his desire for hiking as a way to get to know himself and what he wanted to do in life outside of external pressures despite knowing this experience was not going to advance his degree or career. For Ladybug, a homemaker whose kids recently moved out of the house and went to college, hiking the trail was a long-awaited dream that finally came to fruition. Buffalo, a hiker from Kentucky who also completed his AT thru-hike in 2013, discussed his expectations as a sense of challenge, adventure, and a fellowship with nature. Buffalo also hoped to find some crystallizing formation of who he was as a person. Hikers also saw the trail as a way to decompress from stress. Fern explained that hiking was a way to take time away from her busy life as an attorney in New York City and decompress while also participating in a productive activity. For one retired hiker, the trail was an alternative to sitting on the couch and rereading the same books over again.

The majority of the hikers had some previous hiking or camping experience, which contributed to prompting them to do a longdistance backpacking trip. A few hikers also mentioned their family or coworkers' reaction towards them thru-hiking. Families or coworkers generally did not understand why they would subject themselves to something like a thru-hike. Aqualad expressed, "My family members don't get it and not many people would get it." Upon leaving his job, Mash shared that he told his coworkers, "Before I quit I said I was gonna be a nomadic forest hobo. That's my job description now." When asked what their response was, he stated, "I mean nobody really gets it. Except for the few people that have actually backpacked and know a little bit about it."

\section{Experience on the Trail \\ Being in nature}

Many people today see the demands of modern life as being distinctly removed from nature. Between school, work, and family life, many people in North American society are not 
Table 1. Demographic information of all hikers interviewed

\begin{tabular}{|c|c|c|c|c|c|c|c|c|c|}
\hline Name & Age & Gender & Residence & Education & $\begin{array}{l}\text { Race/ } \\
\text { Ethnici- } \\
\text { ty }\end{array}$ & Employment & $\begin{array}{l}\text { Hike } \\
\text { d AT/ } \\
\text { LT } \\
\text { prior }\end{array}$ & $\begin{array}{l}\text { Socioeconom- } \\
\text { ic status }\end{array}$ & AT/LT completed \\
\hline Aqualad & 20 & Male & $\begin{array}{l}\text { Québec, } \\
\text { Canada }\end{array}$ & $\begin{array}{l}\text { Current } \\
\text { Bachelor's }\end{array}$ & White & $\begin{array}{l}\text { student/ } \\
\text { barista }\end{array}$ & yes & $\begin{array}{l}\text { somewhat } \\
\text { comfortable }\end{array}$ & beginning \\
\hline Buffalo & 28 & Male & Kentucky & Bachelor's & White & $\begin{array}{l}\text { cook/lab } \\
\text { technician }\end{array}$ & yes & $\begin{array}{l}\text { somewhat } \\
\text { comfortable }\end{array}$ & completed \\
\hline Shirt & 25 & Male & $\begin{array}{l}\text { South Car- } \\
\text { olina }\end{array}$ & Bachelor's & White & $\begin{array}{l}\text { mechanical } \\
\text { eng./ no job }\end{array}$ & yes & $\begin{array}{l}\text { very } \\
\text { comfortable }\end{array}$ & 3/4 completed \\
\hline Boondoc & 27 & Male & $\begin{array}{l}\text { Massachu- } \\
\text { setts }\end{array}$ & Bachelor's & White & bar manager & no & $\begin{array}{l}\text { somewhat } \\
\text { comfortable }\end{array}$ & completed \\
\hline Mash & 31 & Male & New York & Bachelor's & White & $\begin{array}{l}\text { mechanical } \\
\text { eng./ no job }\end{array}$ & yes & comfortable & $3 / 4$ completed \\
\hline Pilot & 27 & Male & $\begin{array}{l}\text { Massachu- } \\
\text { setts }\end{array}$ & Bachelor's & White & pilot & yes & $\begin{array}{l}\text { very } \\
\text { comfortable }\end{array}$ & completed \\
\hline Route & 25 & Female & Georgia & Bachelor's & White & $\begin{array}{l}\text { legal proof- } \\
\text { reader }\end{array}$ & yes & $\begin{array}{l}\text { very } \\
\text { comfortable }\end{array}$ & 3/4 completed \\
\hline Ladybug & 53 & Female & Maryland & Bachelor's & White & homemaker & yes & $\begin{array}{l}\text { very } \\
\text { comfortable }\end{array}$ & 3/4 completed \\
\hline Fern & 29 & Female & New York & $\begin{array}{l}\text { Law de- } \\
\text { gree }\end{array}$ & White & attorney & yes & $\begin{array}{l}\text { very } \\
\text { comfortable }\end{array}$ & 3/4 completed \\
\hline Grove & 25 & Male & $\begin{array}{l}\text { South Car- } \\
\text { olina }\end{array}$ & $\begin{array}{l}\text { High } \\
\text { school }\end{array}$ & White & none & no & comfortable & 3/4 completed \\
\hline $\begin{array}{l}\text { Lightning } \\
\text { Shank }\end{array}$ & 19 & Male & $\begin{array}{l}\text { Connecti- } \\
\text { cut }\end{array}$ & $\begin{array}{l}\text { High } \\
\text { school }\end{array}$ & White & none & no & comfortable & beginning \\
\hline Blister & 18 & Male & Virginia & $\begin{array}{l}\text { High } \\
\text { school }\end{array}$ & $\begin{array}{l}\text { Mixed, } \\
\text { White/ } \\
\text { Filipino }\end{array}$ & none & yes & $\begin{array}{l}\text { very } \\
\text { comfortable }\end{array}$ & beginning \\
\hline Straggler & 65 & Male & $\begin{array}{l}\text { Washing- } \\
\text { ton DC }\end{array}$ & $\begin{array}{l}\text { Juris Doc- } \\
\text { tor }\end{array}$ & White & retired & yes & $\begin{array}{l}\text { very } \\
\text { comfortable }\end{array}$ & beginning \\
\hline
\end{tabular}

required to spend time outside. Long-distance backpacking is a way to do something different, an activity that contrasts with our modern lives. Upon asking the thru-hikers how spending extended periods of time in nature while on the trail affected them, many responses ensued: it elicited feelings of connection to themselves, their thoughts, their moods, and sleep; increased their sense of spirituality and brought them into the present moment; and disconnected them from modern influences such as technology, phones, and the media.
Buffalo described the effect that nature had on him as connecting him to the natural world, or what he described as "primal nature" and "a sense of evolutionary heritage": "It definitely made me a happier person. And I think I have to associate being in nature with being active in nature. I sweated through the summer and walked through the rain in the spring. I knew the seasons, but I had never really experienced the subtle changes between them. The world is just so alive. That was kind of humbling." 
Lightning Shank discussed how spending time in nature on the trail simplified his life by forcing him to prioritize his primary needs such as food, water, and shelter over unnecessary and luxurious secondary needs. Fern discussed how living outside away from cellular and internet service forced her to disconnect from being immediately engaged with news media, which lessened her emotional reaction to the information. For Ladybug, being in nature brought her more into the present moment because she needed to be alert and tend to her basic survival means. Many of the hikers also discussed how their waking and sleeping pattern is enforced by the cycles of sunrise and sunset. In general, hikers expressed the positive effects that nature had on their overall mental, emotional, and spiritual states. By spiritual, I do not mean in a religious sense, but rather $a$ connection to the natural world or nourishing the human spirit by connecting to nature. As Pilot stated, "I have been always convinced that the basis of my spirituality revolves around nature. I feel most connected to it when I'm deepest in nature... like when I find myself alone just gazing out at a vast landscape."

\section{Gaining confidence}

Almost all of the thru-hikers that I interviewed discussed how the trail has helped them gain confidence in outdoor skills, self-reliance, and self-confidence as they became more proficient in backpacking and overcame obstacles on the trail. Fern stated how thru-hiking has built her outdoor skills and has sparked her interest in becoming more proficient in other outdoor activities, such as skiing, rock climbing, bike packing, and fishing. Pilot talked about how hiking the trail taught him that goals can be accomplished through breaking tasks down into manageable sections and to keep going until the goal is achieved. Ladybug mentioned how her experience has instilled a trust that things will work out instead of worrying about how things can go wrong.

In contrast to building confidence, hiking the trail allows time to self-reflect, which may provoke confusion through experiencing thoughts and anxieties about the future, especially for young adults contemplating their lives and careers. Overall, hikers primarily discussed how building backpacking skills and physical endurance transferred into generalized feelings of self-reliance and self-confidence.

creating community on the trail and trail families

Likened to the community on the trail and the spirit of that community is a term used in anthropology and the social sciences: communitas. Communitas refers to an unstructured group of people who have an intense spirit of community cultivated by a shared common experience, usually through a rite of passage. Members of the communitas are also viewed as being equal (Turner 1969). The community of thru-hikers on the trail is a diverse group coming from different stages in life with an array of backgrounds that are sharing the same experience. Hikers spend all day walking alongside other hikers, sharing food and other resources, gathering together at the end of a long day to eat dinner, sometimes have a fire, and go to bed. Hikers' process of self-reflection is also embedded in a community, as seen when hikers reflect on their experiences of communal bonding through talking, sharing, and being part of a trail family. When asked about the community on the trail, hikers expressed positive characteristics such as hikers being genuine, kind, and generous.

Blister's observation of how community is formed on the AT is through people sharing a difficult experience with one another. Shirt discussed how strong bonds are formed between hikers through spontaneous, open, and friendly interactions and by means of walking alongside another hiker all day. Route, a young AT thru-hiker from Georgia, discussed how the trail brings a sense of identity that is unified by the mere fact that everyone is out on the trail enduring the same conditions. Route also talked about her experience of hikers showing kindness and compassion towards one another regardless of their different backgrounds, social status, or belief systems. Route stated:

I think out here we actually have way more in common than we don't. People are a lot less judgmental on the trail. People are much more accepting and compassionate and always willing to help out here. Because I think we all know the level of suck that everyone's going through. In real life people 
aren't that way. I feel like you really get in touch with yourself and humanity out here. I feel like out here people are in the rawest form of themselves.

Fern also talked about the concept of a trail family or "tramily," which are close bonds formed between hikers often coming from very different backgrounds. Two of the men that Fern was hiking with had G.E.D.s while she was an attorney in NYC, and the other hiker was a dermatologist who attended Harvard. She noted how she normally did not have meaningful conversations with people who are not at least college-educated in her "real life" (i.e. life prior to the trail).

Pilot further discussed the communal experience of sharing that occurs between members of trail families. Pilot states:

The four of us all hiked together as this little posse for a long time. We had this little communal thing going on, as we would just share everything. When you're isolated like that and you don't have immediate access to a store, sharing helps. That has modified the way I feel about individual possessions, generosity, and thinking about other people. It builds community when a group of people takes care of each other like that.

Interestingly, Straggler, an older hiker who identified as an introvert, mentioned how he expected to have more time alone on the trail; instead, he discovered how populated the trail was and how there is more community on the trail than in his everyday retired life. His statement displays an alternative perspective on the trail community.

In general, hikers reported a renewed sense of humanity through their experiences with other hikers and those who support the trail community. Buffalo, who had hiked the trail six years prior to this study, looked back on his experience of community on the trail, which revived his faith in people. Buffalo commented: "My perspective on inner human connectivity shifted massively. I began to find a lot more value in small group connections. I find much more value in building and maintaining relationships with people that share a space with you."

\section{Enduring discomfort}

Long-distance backpacking on the Appalachian Trail or Long Trail presents a set of challenges in contrast to everyday life. Throughout my discussions with the thru-hikers, a recurring theme that arose was the hikers' ability to endure physical discomfort on the trail. Fern discussed how adjusting to the freezing temperatures at night during the early months on the trail was difficult. Fern also endured numerous physical ailments while on the trail, including blisters that lasted 300 miles and hurt ankles that she supported with ankle braces. Three quarters into her hike, she stated that she had dealt with her conditions and had now transcended the hiking pains and was comfortable hiking. Blister discussed enduring discomfort and being comfortable with the uncomfortable. Buffalo shared a memory of enduring the freezing cold days on the trail and realizing how if he wanted to reach the end of the trail, Mount Katahdin, then he would have to persist through the situation.

Mash reflected that "there are no easy days on the AT. Some are just more fun than others." While on the trail, the hikers learn to endure discomforts such as blisters, joint pain, freezing temperatures, and rain. Persisting through challenges that arise on the trail plays a role in hikers' forming confidence as they gain a new self-appreciation when they overcome physical discomfort.

\section{Personal Reflections \\ Insights on the trail}

Many of the hikers shared personal reflections that they had while on the trail. Younger hikers reflected on their future aspirations while older hikers tended towards a review of their lives. As previously noted, many of the thru-hikers attempted the trail during a transition in their lives. The trail provided them with time and space to be free from distractions and concentrate on their own thoughts and feelings about important matters. Some discovered that spending time with themselves to reflect on their life or what was to come was just what they needed.

Pilot discussed that having time with his thoughts allowed him to develop a way to consider the different courses that he could 
take in his life. In his everyday life, he would usually become distracted by something else and move onto another idea. Shirt reflected that one can deliberately change one's experience through positive thinking. He also discussed thinking bigger in terms of the things that he wanted to do, and then taking the leap towards doing those things instead of just dreaming about them. For him, this meant becoming self-employed. Blister, who shared that he had bipolar disorder, realized that he enjoyed the effect hiking had on quieting his mind. When asked about any personal reflections he had while on the trail, Mash pulled out a little notepad in which he wrote his personal insights. "Every year I think it's important for us to take time to slow down. Too much of our lives are spent rushing to nothing. Life is a struggle and it's about simple things like a beautiful view, lunch with friends."

Many hikers also discussed how only carrying one's essential needs on their back made them more inclined to a minimalist philosophy. They translated this reflection into thinking about their lives back home, where they felt they could do with much fewer possessions. As Pilot recognized, "just all the extraneous crap that you'll hold onto during your life. Like when I got back I went into my room and was like what is all this crap. I don't need any of this. I just became way more minimalist in terms of what possessions I wanted to hang on to."

\section{Trail culture versus life before and after the trail}

The culture on the trail is a subculture in which there is a unifying identity between members who belong to it and a set of norms and values that are different from dominant North American society. As discussed earlier, this new group bond and altered values and norms connects with Turner's (1969) concept of communitas. Hikers' individual experiences may vary depending on who they are hiking with, as there is no written rulebook for the trail; however, many of the norms are an unspoken set of values that hikers abide by while on the trail. One value thru-hikers on the AT/LT abide by is the motto "Leave No Trace," which simply means to pack everything one brings on the trail back out with them for proper disposal.
Hikers on the trail form a tight-knit community that lends itself to being kind and considerate towards other hikers. When asked about how the culture on the trail differs from the culture hikers typically experience in everyday life, the hikers mainly focused on how open, laidback, considerate, friendly, and more tolerant of free expression hikers were on the trail. Hikers also discussed how other hikers were a lot less judgmental than people in everyday life. There is a lower standard of personal hygiene on the trail due to the lack of amenities available. Shirt points out, "Nobody really cares what you're doing as long as you're not affecting others. Nobody is judging if you hike five or fifty miles that day." Another hiker, Boondoc, talks about how hikers pile up in the shelters, sleeping next to a stranger in the middle of the woods, and how in everyday life that is far from what is considered normal. Buffalo stated:

There's a fraternity amongst thru-hikers that comes from suffering together and sharing a unique experience together. On the trail people assume different identities and it comes out in the trail names. There's definitely less of an expectation for a poised presentation of yourself. People forgo a lot of pleasantries or things that might not necessarily be polite, like belching or flatulating without hesitation. The trail definitely encourages you to be a genuine form of yourself and to just experience the trail in a way that responds to you. There's a sense of social liberation on the trail. Like there's no one really readily observing or judging you, but almost encouraging you to be free.

Buffalo's reflection suggests communitas in how thru-hikers on the AT share a unique experience together that facilitates a strong bond. The liberating freeform expression on the trail also displays the spirit of the community that is encouraged on the trail.

Mash talked about how it is not very often that you are surrounded by a community of people chasing their dreams: people who have made sacrifices to be out on the trail. Mash also referred to the hiker community as "a band of hobos walking together" because nobody who is thru-hiking is currently working or owns a 
house while on the trail. This suggests the removal of common markers of social status such as jobs and housing. Also noting the lack of socioeconomic markers, Ladybug stated:

The community at home is more based on geographic location, socioeconomics, and who's doing the same things. Out here you could be sitting around at a picnic table having just met people that you all have this common thread, of such a powerful experience. You could have some 20-yearold from France and a 32-year-old from Denmark and me being a 53-year-old and a 70-year-old guy or something and we're all just chatting. And in real life that probably wouldn't happen unless you're like in a support group and you're forced to come together.

Pilot mentioned that the absence of resources on the trail makes it necessary for hikers to have each other's backs, which reinforces the trail families. When hikers realize that food and resources are scarce, they are more apt to take care of one another. It also makes resources much more valuable, whereas for most hikers, in everyday life food and supplies are in excess and therefore are much more disposable, causing these items to lose their value. Another notable response from Pilot was that hikers are much friendlier than people in his everyday life: "Everybody on the AT is very open. There is way less of this bullshit of everybody intrinsically hating each other and not wanting to talk to one another. In Boston, if you talk to a stranger, five out of ten times that's not going to go well. On the AT if you want to start like a 30-minute conversation, anybody was down at any time."

Fern also mentioned one group of hikers she found herself in who had the motto "no goals." This can be seen as a reaction to how efficacy, productivity, and goals are fundamental driving values of modern North American culture. This motto displays how trail life is radically different, almost an antithesis, to everyday life in modern culture.

However, not all aspects of trail culture were viewed positively. As Fern points out, the trail is mostly white, masculine, and privileged, and one unspoken rule is to not talk about politics:
There's a real attitude about no politics on the trail or don't talk about race, religion, or whatever on trail. I understand the value of doing that and that we're out here to have a certain experience. But $\mid$ find it uncomfortable because I think it's a really privileged position to take. I don't like that people can say that in order to avoid difficult conversations. I think the trail is very masculine, it's very white, it's privileged. Out here there's kind of a culture of putting it to rest and not having the conversation, in a way that gets under my skin.

Pilot also discussed how trail culture promotes many male hikers to grow out their beards, build muscles, drink a lot of beer, and carry large and heavy items such as watermelons from towns onto the trail.

Fern and Pilot's statements display that even though there is an ideal of equality amongst thru-hikers, which aligns with the dissolution of social status typical of communitas, the trail as a whole is still highly masculine. While individual experiences may vary, this gender inequality creates a contradiction between ideology and practice.

\section{Hikers' views of society}

During the interviews, I asked the thru-hikers about their views of modern society in North America-many responses were negative. Buffalo discussed how his view of society had become more calloused over time and how there was something to be gained by being removed from it for the six months while he was on the trail. Buffalo discussed the divergence between institutional bureaucracy versus hiking the trail. He said that if you want to hike the AT, you just physically do it; you can succeed as a result of your own actions in contrast to institutions where extensive certifications are required to get credentialed for a job. Shirt shared his view:

I have just been reaffirmed that people are trapped because they want to trap themselves. When you do this you meet so many people who are like I wish I could do that or people live vicariously through social media. And it might not be the AT for most these people but they have something they've wanted to do their whole lives, but 
instead of following their dream, they make excuses. I understand I have the privilege, but there are people with the same opportunities as me that are doing the same rat race bullshit that everybody else is. So I have sympathy for people but at the same time sometimes it's useful to grab them and shake them and be like you can do this too. Just don't wait till you're dead.

Shirt's statement suggests that there are multiple social realties in which one is able to make conscious choices about different paths in life and decide which reality to accept. This speaks to how an experience like thru-hiking the AT facilitates a proactive mindset amongst thru-hikers and encourages those with the means to do so to continue exercising their ability to pursue their dreams and goals after thru-hiking

Route also discussed how life on the trail contrasted with modern society: "I think everybody in the world needs to come hike the AT just because it's raw, it's real. There's no façade to hide behind. No money, no car, no job, no marriage, whatever. It's just depressing thinking about real life. The closer we get to Maine the more I'm like don't make me go back!" Route's statement connects to liminality in that her pre-trail life no longer exists; the trail is an intermediate phase and she had not yet begun reintegrating into her post-trail life. Route's discussion of the trail as raw in the sense that there is no social structure to mask one's identity speaks to how the trail displays Turner's (1969) concept of anti-structure. With the absence of typical indicators of social status or success while thru-hiking, the trail may be viewed as a revolt against the structure that is imposed on people in everyday society. Route's statement also exemplifies the phenomenological view of identity construction in that the trail has exposed her to an alternative social reality that she can choose to accept or not. In doing so, she then internalizes her chosen reality, and through this intentional choice, either constructs a new identity or reverts back to her previous identity.

Overall, the hikers' views mostly demonstrated how the trail was in juxtaposition to their usual roles in society. They talked about how the trail renewed their faith in humanity and provided them with a sense of freedom in ways that being involved in their everyday social interactions did not. Hikers discussed the culture on the trail almost as finding a new sense of reality apart from the norms of society: a stripping off of all the structures that keep people apart from nature and one another. At the same time, this itself becomes a part of the structure on the trail.

\section{Impact of Hiking the Trail}

The hikers I spoke with who were about a week into their hike were uncertain of how the trail was going to impact their lives, whereas the hikers who were three-quarters of the way through their hike or had completed their hike discussed how the trail had built their selfreliance, confidence, and self-directedness. Most of the hikers talked about feeling mentally and physically stronger from hiking the trail. Many hikers also mentioned that thru-hiking reaffirmed previously held beliefs about themselves and what they are capable of.

Buffalo considers the trail to be one of the greatest experiences of his life. He shared that in his office he has three things on the wall: his Appalachian Trail certificate, his Pacific Crest Trail certificate, and a photo of his deceased mother. Buffalo also mentioned how his sense of identity was formed by achieving his goal of reaching the end of the trail and by the new experiences, people, and places he interacted with while on the trail.

\section{Reintegration and changes made}

I asked the hikers how they thought they would integrate their experience back into their everyday lives and what lifestyle changes they anticipated making after completing their hike. Most of the respondents immediately mentioned their hesitations of acclimating back into everyday life. Hikers were concerned about losing the state of mind they cultivated on the trail and dealing with the monotony and stress of everyday life, which included work for most of the hikers. Some even mentioned their fear of post-trail depression, which is a topic discussed on the trail. Every hiker mentioned decreasing their caloric intake and increasing exercise in post-trail life. Hikers also discussed how living with the motto "Leave No Trace" has made them want to live in a more environmentally conscious manner. Hikers who 
completed the trail talked about getting rid of clothing and other belongings post-trail. Many hikers discussed how the trail has developed their attitude towards putting dreams into action rather than postponing them. Grove stated that he was going to pursue more things for happiness rather than just money or social status. Ladybug shared her interest in planning another thru-hike to get her through the dark days after the trail. Lightning Shank said he was not going to start paying for Netflix again and that he was going to try and simplify his life to reflect the way of life on the trail.

The three hikers, Boondoc, Buffalo, and Pilot, who hiked the AT six years prior felt their experience had long term benefits and that thru-hiking was one of the most significant experiences in their lives. They believed it had given them a sustained sense of confidence, self-reliance, and grit. These hikers also mentioned their continued interest in hiking, completing other thru-hikes, and trail conservation values. In contrast to these long term effects of thru-hiking the AT, when Buffalo was asked how his views on society changed from this experience, he replied, "I think that for a time they did change and then I slowly became more calloused as I reintegrated back into society. I felt that there was something to be gained from not participating in the rigidity of the American lifestyle for so long." Buffalo also discussed how initially upon reintegrating into the larger society he had felt like an outsider because others could not relate to this radical experience he had just emerged from. This is an example of reincorporation, a postliminal phase, which is the third stage of a rite of passage as explained by Turner (1969).

\section{Discussion of Interviews with Long-Distance Hikers}

Analysis of the 13 interviews conducted for this study suggests that hikers understand thruhiking the Appalachian Trail or Long Trail as a way to navigate a transition in their life, decompress from the stress of a job, gain perspective or get to know themselves better, take an opportune time to fulfill a personal dream, and to experience a challenge, freedom, and adventure. Long-distance backpacking is also viewed as resistance to contemporary society, an activity that contrasts with our modern lives. Upon asking the thru-hikers how spending extended periods of time in nature on the trail affected them, many described how hiking elicited feelings of a connection to themselves and nature. Hikers stated how hiking and being in nature helped stabilize their thoughts, moods, and sleep. Some mentioned how being in nature brought them into the present moment and even elicited a sense of spirituality. Hikers also mentioned that being disconnected from modern influences such as technology, phones, and the media had a positive effect on them and how being in nature connected them to what one hiker described as a more "primal" sense of themselves. They further explained how being in nature simplified life down to the basics and allowed them to let go of extraneous possessions and influences.

Thru-hiking had a positive impact on hikers' self-perceptions, making them feel mentally, emotionally, and physically stronger. Hikers discussed gaining confidence as they became more proficient in their outdoor skills, increased their physical endurance, and built connections to the community on the trail. Hikers' feelings of self-confidence and selfreliance translated into how they thought about other areas of their lives. Their boost in confidence inspired them to dream bigger and take action towards their dreams, knowing that they could set a goal and achieve it by focusing on one step at a time.

In this study, phenomenology was a helpful theoretical perspective to understand how hikers make sense of the juxtaposition of the culture and community on the AT/LT in contrast to their everyday lives off the trail. This exposure to an alternative culture on the trail allowed hikers to question their lives prior to the trail and formulate a new sense of identity and reality through internalizing the culture on the AT/LT. Hikers displayed this by adopting trail names and through assimilating to the unspoken values of the trail. The data suggests multiple experiences on the trail, including both individual self-reflection and communal bonding. As the experiences of thru-hikers vary, individuals choose how to respond to the particular situations they face on the trail, whether it involves adjusting their mindset, 
enduring pain and bad weather, stopping at a trail town, or setting their own schedule and goals. Individual decision making is a cultural norm on the trail that is reinforced by both hikers' expectations of life on the trail and interactions with other hikers.

Communitas was formed on the trail through the creation of an ad-hoc community by virtue of hiking and sleeping next to other hikers. Through this process, "trail families" that travel as little tribes are formed. Hikers discussed members of the community as being genuine, outgoing, and accepting. Nonjudgment and trust are valued on the trail, which brings people from all different backgrounds, belief systems, and jobs together. Generosity and sharing are also encouraged as a tight-knit community is formed and resources are limited. The complexity of life on the trail is reflected in the contrast between the social and individual aspects of trail life: while hikers' experiences are embedded in communitas and the unique bonds they form within their trail families, many undergo processes of individual reflection and identity reconstruction simultaneously.

Long-distance backpacking on the AT/LT presents a different set of challenges in contrast to everyday life. Hikers learned the ability to overcome challenges such as poor weather, physical ailments, and mental and/or emotional struggles while on the trail. Hikers discussed having the time for self-reflection and being in nature as a rejuvenating healing process. Their insights on the trail reflected on the importance of slowing down, having a sense of personal agency, and the benefits of taking time away from distractions to reflect upon one's life.

The culture on the Appalachian Trail or Long Trail can be viewed as a subculture in which there is a unifying identity between members who belong to it; it is a subculture with its own set of norms and values different from the dominant society. There is no written rulebook for the trail-many of the norms are an unspoken set of values that hikers abide by on the trail, such as the motto "Leave No Trace."

Hikers also discussed how the lack of resources on the trail increased the value of material goods in contrast to modern life where resources are in excess and more disposable, making them less valuable. Fern mentioned how one of her trail families had a rule of "no goals," which can be seen as a rejection of the emphasis on goal-driven behavior in contemporary society. This connects to liminality in the sense that hikers undergo a restructuring of their identity, values, and behaviors while on the trail. In turn, this allows them to formulate a new way of life as they end up identifying more with the culture on the trail compared to their previous way of life.

Hikers' views of society included skepticism towards larger institutions and encouraged belief in grassroots organizations. Hikers' views mostly reflected on the juxtaposition between life on the trail and being involved in society. They talked about how the trail renewed their faith in humanity and provided them with a sense of freedom in ways that being involved in society did not. As suggested by a phenomenological analysis, hikers discussed the culture on the trail almost as if they had found a new sense of reality apart from the norms of society. For them, the AT/LT contrasts with mainstream society in that people are considered more equal on the trail: there are no façades such as money, a job, car, or marriage to hide behind. However, as Fern discussed the idea of equality that is embedded in communitas and on the trail is contradicted by the reality that the trail is highly masculinized, white, and privileged.

Thru-hiking impacted hikers by building their self-reliance, confidence, and self-directedness. Hikers reported being reaffirmed of their previously held beliefs about themselves and what they are capable of. Hikers noted that time on the trail made them more relaxed and community-oriented. Many hikers also discussed how carrying only one's essential needs on their back taught them to become a minimalist. Hikers also noted becoming more environmentally conscious.

Hikers shared their concerns about reacclimating back into everyday life, losing the state of mind that they cultivated on the trail, and dealing with the monotony and stress of everyday life. The three thru-hikers who were interviewed six years after completing the AT discussed having prolonged feelings of 
confidence, self-reliance, and grit from having been tested through their experience on the trail.

\section{Concluding Thoughts}

By providing an in-depth analysis of hikers' personal reflections about hiking, this research contributes to our knowledge of how hikers make sense of their experiences long-distance backpacking the Appalachian and Long Trail. Unlike previous studies, this study also introduces the concept of phenomenology as a theoretical lens and utilizes the analytical concepts of liminality and communitas. This theoretical approach illuminates how hikers form a new sense of identity and reality on the trail, as well as an altered perception of their prior social roles and activities.

While demographic information regarding gender, race/ethnicity, and socioeconomic status was collected, examining how these variables may alter the meaning and experience of long-distance hiking is not the main focus of this research, mainly due to the limited number of participants. Notably, unlike earlier studies of thru-hikers, not all participants in this study identified as white-one identified as white/ African American and another as white/Filipino. An analysis of racial and ethnic diversity, gender, and socioeconomics of the population of long-distance hikers is an important area for continued research. Climate change could also be a theme of further research of thru-hikers on the Appalachian Trail or Long Trail due to the impacts of increasing droughts, wildfires, unpredictable winters, rising sea levels, and other natural disasters on hiking conditions (Sarae 2020). Finally, future research could continue to expand upon the role of personal reflection in facilitating meaningful change by interviewing hikers periodically for several years after completing their hikes.

With regard to my personal experience completing this study, going back out on the trail and interacting with the hikers after six years refreshed my sense of the spirit of hikers on the trail. I was delighted to still feel welcomed into the community as I asked thruhikers for their participation in this research. Hikers were more than willing to participate and showed thoughtfulness in their responses.
It was also wonderful to reach out to fellow hikers from 2013 to hear about their experiences of the trail as well as to relive some shared experiences. Further, this research renewed my own inclination to take the time to retreat into nature in order to slow down and self-reflect. 


\section{Acknowledgements}

I would like to endlessly acknowledge and thank my thesis advisor, Dr. Susan Thomson Tripathy, for working closely with me in facilitating this research project. Without all of her dedication, guidance, and support this paper would not be possible. I would also like to thank Dr. Mignon Duffy and Dr. Marlowe Miller for editing and encouraging this research paper, as well as Dr. Egan who introduced me to some of the concepts used in this research. Lastly, I would like to thank the hikers who so generously took the time to share their experiences on the AT/LT with me. 


\section{References}

Berger, Peter L., and Thomas Luckmann. 1966. The Social Construction of Reality: A Treatise in the Sociology of Knowledge. New York, New York: Penguin Books.

Bosche, Lucy L. 2013. "Woman into the Wild: Female Thru-hikers and Pilgrimage on the Appalachian and Pacific Crest Trails." Undergraduate thesis, Scripps College.

Bratton, Susan Power. 2012. The Spirit of the Appalachian Trail: Community, Environment, and Belief. Knoxville, TN: University of Tennessee Press.

Desjarlais, Robert, and Jason Throop, C. 2011. "Phenomenological Approaches in Anthropology." Annual Review of Anthropology 40 (1): 87-102.

Esterberg, Kristin G. 2002. Qualitative Methods in Social Research. Boston: McGraw Hill.

Fondren, Kristi M. 2016. Walking on the Wild Side: Long-distance Hiking on the Appalachian Trail. New Brunswick, NJ: Rutgers University Press.

van Gennep, Arnold (1909) 1960. The Rites of Passage. Chicago: University of Chicago Press.

Lemert, Charles C. 2017. Social Theory: The Multicultural, Global, and Classic Readings. 6th ed. New York, NY: Routledge.

Ritzer, George, and Jeffrey Stepnisky. 2018. Sociological Theory. 10th ed. Thousand Oaks, CA: Sage.

Moor, Robert. 2016. On Trails: An Exploration. New York, New York: Simon and Schuster.

Sarae, Kenna. 2020. "How Climate Change Affects Long-Distance Hiking." Accessed February 08, 2021. https://thetrek.co/howclimate-change-affects-long-distance-hiking/.

Strayed, Cheryl. 2012. Wild: From Lost to Found on the Pacific Crest Trail. New York: Alfred A. Knopf.

Turner, Edith. 2012. Communitas: The Anthropology of Collective Joy. New York: Palgrave Macmillan.

Turner, Victor. 1969. The Ritual Process: Structure and Anti-structure. Piscataway, N.J.: Aldine Transaction.

\section{(c)}

This work is licensed under a Creative Commons

Attribution-NonCommercialNoDerivatives 4.0 International License. 